\title{
Metachronous Bilateral Acinic Cell Carcinoma of the Parotid Gland in a Young Woman
}

\author{
Dladimír Bartos \\ Department of Pathology, Faculty Hospital in Žilina, Slovakia
}

\begin{abstract}
Bilateral involvement of major salivary glands by carcinoma of an identical histologic subtype is uncommon. In this study, a 26-year old female patient was diagnosed to have a low-grade acinic cell carcinoma (ACC) in the left parotid gland. After superficial parotidectomy, she was referred to the oncological dispensary care without further oncological therapeutic intervention. During 11 years of follow-up, she had no evidence of locoregional recurrence or metastasis. However, at the age of 37 , she was recognized to have another tumor mass in the contralateral parotid gland. Right superficial parotidectomy was done, and histology confirmed an ACC showing the same picture as it was found previously. A year after the operation, no sign of tumor relapse was seen. Although metachronous bilateral ACC of the parotid gland is very rare, it is occasionally encountered in medical practice. Such an event may occur many years after a diagnosis of the initial tumor. Every patient once treated for parotid ACC warrants periodical clinical examinations and long-term follow-up (more than 10 years), even with attention to the contralateral non-affected parotid gland.

Keywords: Acinic cell carcinoma; bilateral involvement; parotid gland.

Please cite this article as "Bartos V. Metachronous Bilateral Acinic Cell Carcinoma of the Parotid Gland in a Young Woman. Med Bull Sisli Etfal Hosp 2019;53(3):306-309".
\end{abstract}

$S_{n}^{a}$ livary gland tumors are a very heterogeneous group of nosological entities with various clinicopathological features and biological behaviour. Acinic cell carcinoma (ACC) comprises about $17 \%$ of all salivary gland cancers. ${ }^{[1]}$ ACC exhibits a serous acinar cell differentiation characterized by cytoplasmic zymogen secretory granules. ${ }^{[1]}$ In contrast to other malignancies, ACC occurs more frequently in young people. More than $16 \%$ of the patients are under the age of $30 .{ }^{[1]}$ In this younger population, female patients comprise a significantly greater proportion of the cases..$^{[1]} \mathrm{ACC}$ is generally restricted (92\%) to the parotid gland. ${ }^{[2]}$ Exceptionally, it may affect both parotid glands in a single individual. Bilateral occurrence may be either synchronous (simultane- ous coexistence at the time of diagnosis) or metachronous (consecutive development after a certain time) in presentation. Only a few such cases have been reported in the literature until now, which remained under-researched. ${ }^{[2-14]}$ this study presents a unique case of ACC with an involvement of both parotid glands in a young woman, in whom the second primary tumor on the contralateral side occurred after a long time from a development of the first lesion.

\section{Case Report}

In 2007, a 26-year old female with unremarkable medical history was diagnosed to have a tumor mass in the left parotid gland. Ultrasonography (USG) revealed a well-de- 
marcated, hypoechogenic solid tumor $14 \mathrm{~mm}$ in diameter, as well as lymphadenopathy in the left side of the neck. A left superficial parotidectomy with a regional cervical lymph node extirpation was performed. Histology of the resected tumor confirmed a low-grade ACC with the neoplastic cell population predominantly arranged in solidlobular pattern and surrounded by a dense lymphoid stroma containing the lymphoid follicles (Fig. 1). Tumor cells contained PAS (Periodic Acid-Schiff) positive (Fig. 2) and diastase-resistant intracytoplasmic granules. Immunohistochemically, they were strongly positive for pan-cytokeratin, CEA, CK7, focally positive for S-100 protein, and neg-

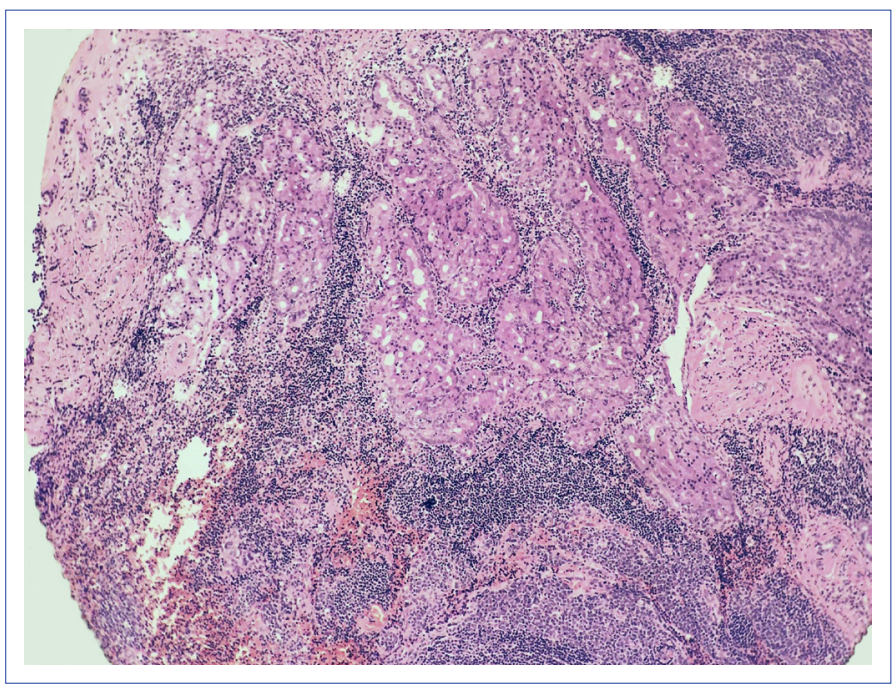

Figure 1. The first ACC arising in the left parotid gland. A solid-nodular growth pattern of the neoplastic epithelium. The tumor cell population resembles normal serous acinar salivary gland cells (hematoxylin \& eosin, 40x).

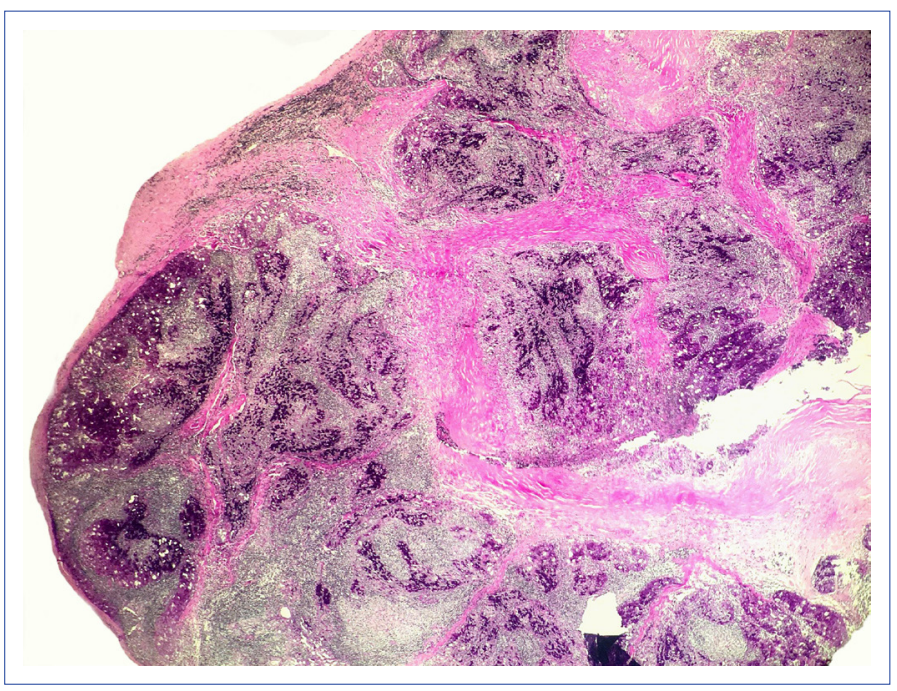

Figure 2. PAS staining (the case presented in Figure 1). A multilobular microarchitecture of tumor tissue. The eosinophilic material in the cytoplasm of the neoplastic cells shows a strong purple color (20x). ative for alpha-SMA. The Ki-67 proliferation index was $<5 \%$. Resection margins were free of tumor. Resected lymph node did not show metastatic infiltration. The patient was referred to the oncological dispensary care without further oncological therapeutic intervention. She underwent regular medical check-ups at the Otorhinolaryngology Department (at least once a year), including USG scans. During a follow-up period (11 years), she had not any signs of local recurrence or metastasis. However, in May 2018, at the age of 37 , she recognized a painless swelling in the right preauricular region, accompanied by cervical lymphadenopathy. Magnetic resonance imaging (MRI) showed an irregular hypoechogenic tumor mass in the right parotid gland. The lesion measured $12 \mathrm{~mm}$, it was multilobulated with no evidence of extraglandular propagation. Positron emission tomography and computed tomography (PET/CT) confirmed an increased accumulation of fluourodeoxyglucose in the lower pole of the gland. A USG-guided core needle biopsy was performed, and microscopy suggested a diagnosis of ACC. Shortly thereafter, a right superficial parotidectomy with a regional lymph nodes dissection was done. Histology confirmed a low-grade ACC showing the same picture as it was found in the left parotid gland (Fig. 3). It immunohistochemically expressed CK7, CK8/18 and CK19, while it was negative for CK20, p63 and alpha-SMA. Neoplastic cells contained abundant PAS-positive, diastase-resistant cytoplasmic granules (Fig. 4). Due to fragmentation and artificial changes of biopsy tissue, it was not possible to reliably comment on the resection margins. All lymph nodes (eight) were free of tumor. After surgery, re-excision of the parotid gland and local radiation therapy were considered, but eventually (with respect to the patient's wish and in an

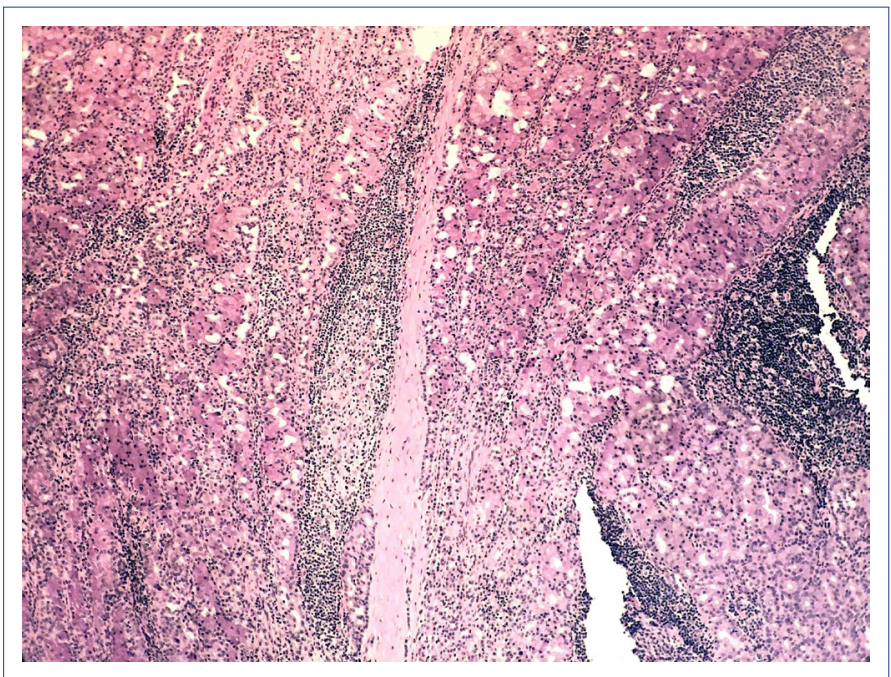

Figure 3. The second ACC arising in the right parotid gland. The tumor has the same microscopic appearanceas in the previous case (hematoxylin \& eosin, 100x). 


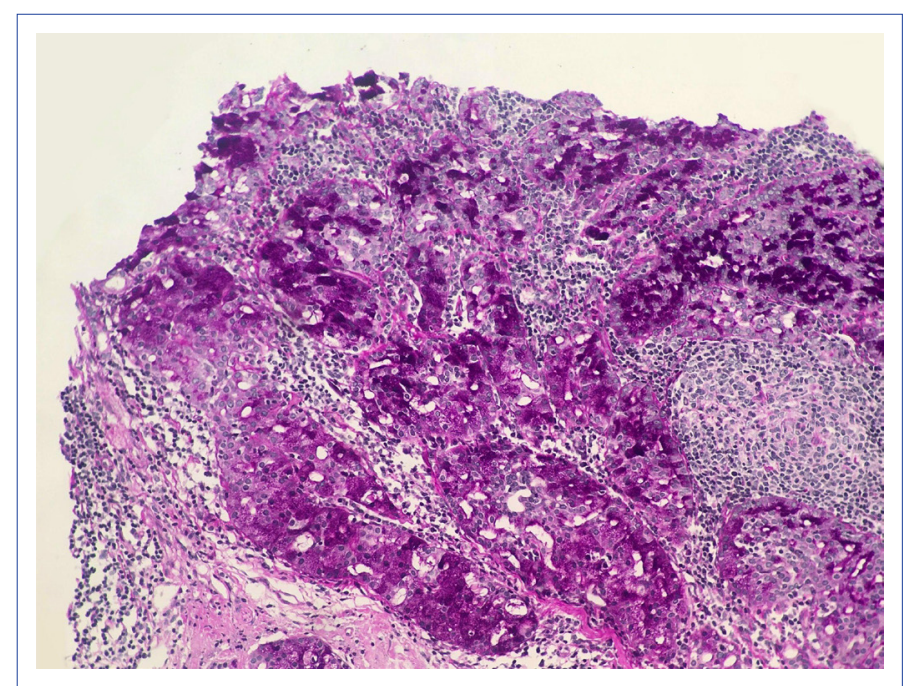

Figure 4. PAS diastase staining (the case presented in Figure 3). Purple color of the neoplastic cells does persist after digestion with a diastase (100x).

effort to avoid facial nerve injury) they were abandoned. The patient underwent stringent medical check-ups, including the imaging exams. A year after the operation, she was without evidence of locoregional recurrence or metastasis.

\section{Discussion}

In routine otorhinolaryngology practice, bilateral involvement of major salivary glands by carcinoma of an identical histologic subtype is uncommon. In this journal, an interesting case report of bilateral synchronous mucoepidermoid carcinoma of the parotid gland has been recently published by Akpinar et al. ${ }^{[15]}$ Among epithelial malignancies, ACC is thought to possess the highest propensity to affect both parotid glands ( $<5 \%$ of all cases) in a single person. ${ }^{[2-4]}$ However, due to the rarity, there are limited data regarding the incidence of this phenomenon. We have found fifteen case reports describing an occurrence of ACC in both parotid glands in one patient that are summarized in Table $1,{ }^{[2-14]}$ including the present case. Mean age of the patients was 49.3 years. Six individuals ( $37.5 \%)$ were young females up to 37 years old age. Most of the cases (75\%) exhibited a simultaneous occurrence of carcinomas in both parotid glands at the time of diagnosis. We have discovered only three patients, in whom the second primary cancer developed in the contralateral parotid gland after a certain period of time from the recognition and treatment of the first tumor. Our patient represents the fourth such case published in the literature. Moreover, among those documented cases, the findings demonstrates the longest interval (11 years) between the diagnosis of both primary lesions. Therefore, there is no doubt that a prolonged follow-up is mandatory after treatment in all cases.
Table 1. A summary of the clinicopathologic findings of the patients manifesting with a bilateral development of ACC in the parotid gland

\begin{tabular}{lccc}
\hline Ref. & Age & Sex & Development of the tumors \\
\hline$(2)$ & 20 & Female & Synchronous occurrence \\
$(3)$ & 50 & Female & Synchronous occurrence \\
$(4)$ & 22 & Female & Synchronous occurrence \\
$(5)$ & 64 & Male & Synchronous occurrence \\
$(6)$ & 52 & Male & Synchronous occurrence \\
$(7)$ & 55 & Female & Synchronous occurrence \\
$(8)$ & $35 / 36$ & Female & Metachronous occurrence \\
& & & (interval 1 year) \\
$(9)$ & 71 & Male & Synchronous occurrence \\
$(9)$ & 55 & Female & Synchronous occurrence \\
$(10)$ & 32 & Female & Synchronous occurrence \\
$(11)$ & 57 & Female & Synchronous occurrence \\
$(12)$ & 77 & Female & Synchronous occurrence \\
$(13)$ & $55 / 58$ & Female & Metachronous occurrence \\
& & & (interval 3 years) \\
$(14)$ & 36 & Female & Synchronous occurrence \\
$(14)$ & $60 / 68$ & Male & Metachronous occurrence \\
& & & (interval 8 years) \\
This case & $26 / 37$ & Female & Metachronous occurrence \\
& & & (interval 11 years) \\
\hline
\end{tabular}

\section{Conclusion}

Although metachronous bilateral ACC of the parotid gland is very rare, it is occasionally encountered in medical practice. This case report demonstrates that such an event may occur many years after a diagnosis of the initial tumor. Every patient once treated for parotid ACC warrants periodical clinical examinations and long-term follow-up (more than 10 years), even with attention to the contralateral non-affected parotid gland.

\section{Disclosures}

Informed Consent: Written informed consent was obtained from the patient for the publication of the case report and the accompanying images.

Peer-review: Externally peer-reviewed.

Conflict of Interest: None declared.

\section{References}

1. Al-Zaher N, Obeid A, Al-Salam S, Al-Kayyali BS. Acinic cell carcinoma of the salivary glands: a literature review. Hematol Oncol Stem Cell Ther 2009;2:259-64. [CrossRef]

2. Clarke JS, Hentz EC, Mahoney WD. Bilateral acinic cell carcinoma of the parotid gland. Ann Surg 1969;170:866-9. [CrossRef]

3. Guha S, Guha R, Manikantan K, Sharan R, Arun P, Mallick I. Synchronous Bilateral Acinic Cell Carcinoma of the Parotid. J Cancer 
Sci Ther 2012;4:92-3. [CrossRef]

4. Durand N, Mourrain-Langlois E, Leclair F, Malard O. Synchronous bilateral acinic cell carcinoma of the parotid: when a tumor reveals another one. Eur Ann Otorhinolaryngol Head Neck Dis 2013;130:22-5. [CrossRef]

5. Delides A, Velegrakis G, Kontogeorgos G, Karagianni E, Nakas D, Helidonis E. Familial bilateral acinic cell carcinoma of the parotid synchronous with pituitary adenoma: case report. Head Neck 2005;27:825-8. [CrossRef]

6. Ho G, Jankowska P, Perrin R, Banks R, Teoh E, Harrington K. Dosimetric Problems of Radiotherapy to Synchronous Bilateral Acinic Cell Carcinoma of Parotid Glands. Clin Oncol 2007;19:S31. [CrossRef]

7. Jia YL, Bishwo SP, Nie X, Chen LL. Synchronous bilateral multifocal acinic cell carcinoma of parotid gland: case report and review of the literature. J Oral Maxillofac Surg 2012;70:e574-80. [CrossRef]

8. Di Palma S, Corletto V, Lavarino C, Birindelli S, Pilotti S. Unilateral aneuploid dedifferentiated acinic cell carcinoma associated with bilateral-low grade diploid acinic cell carcinoma of the parotid gland. Virchows Arch 1999;434:361-5. [CrossRef]

9. Diamant $\mathrm{H}$, Eneroth $\mathrm{CM}$, Gejrot T. Bilateral tumors of the parotid gland. J Laryngol Otol 1961;75:699-702. [CrossRef]

10. Dunn EJ, Kent T, Hines J, Cohn I Jr. Parotid neoplasms: a report of 250 cases and review of the literature. Ann Surg 1976;184:500-6.

11. Levin JM, Robinson DW, Lin F. Acinic cell carcinoma: collective review, including bilateral cases. Arch Surg 1975;110:64-8. [CrossRef]

12. Millar BG, Johnson PA, Leopard PJ. Bilateral acinic cell carcinoma of the parotid. Br J Oral Maxillofac Surg 1989;27:192-7. [CrossRef]

13. Nuutinen J, Kansanen M, Syrjänen K. View from beneath: pathology in focus bilateral acinic cell tumours of the parotid gland. J Laryngol Otol 1991;105:796-8. [CrossRef]

14. Turnbull AD, Frazell EL. Multiple tumors of the major salivary glands. Am J Surg 1969;118:787-9. [CrossRef]

15. Akpinar M, Unsal O, Cankaya M, Tetik F, Uslu Coskun B. Bilateral synchronous mucoepidermoid carcinoma of the parotid gland. Med Bull Sisli Etfal Hosp 2018;52:145-8. [CrossRef] 